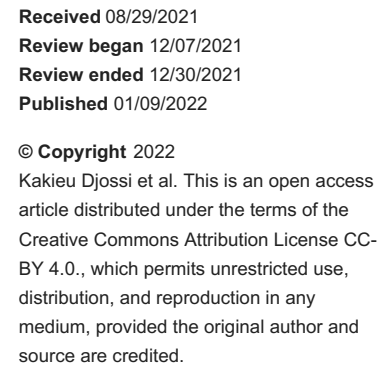

\section{Food Allergy Prevention: Early Versus Late Introduction of Food Allergens in Children}

\author{
Sandrine Kakieu Djossi ${ }^{1}$, Anwar Khedr ${ }^{2}$, Bandana Neupane ${ }^{3}$, Ekaterina Proskuriakova ${ }^{2}$, Keji Jada ${ }^{3}$, Jihan \\ A. Mostafa ${ }^{4}$ \\ 1. Medical Research, California Institute of Behavioral Neurosciences \& Psychology, Fairfield, USA 2. Internal \\ Medicine, California Institute of Behavioral Neurosciences \& Psychology, Fairfield, USA 3. Research, California \\ Institute of Behavioral Neurosciences \& Psychology, Fairfield, USA 4. Psychiatry, California Institute of Behavioral \\ Neurosciences \& Psychology, Fairfield, USA
}

Corresponding author: Sandrine Kakieu Djossi, kakieu2014@gmail.com

\begin{abstract}
The emergence of food allergies in children is crucial for various medical fields seeking a viable strategy for allergy prevention. The most well-recognized approach adopted by numerous health care and government institutions hinges on the delay in the introduction of food allergens, which supposedly protects infants from sensitization and decreases the possibility of allergy development. However, recent experimental findings indicate that the benefits of this approach might be overestimated, as early exposure to allergenic foods has been shown to yield more advantageous outcomes. Multiple investigations on the causes of allergic diseases report that avoiding food allergies might be related to early consumption of these allergens. Alternatively, delaying the contact with allergenic nourishments, explored in contemporary research, has been proven to result in a higher prevalence of allergies among children, originating such conditions as atopic diseases and extreme sensitization to foods. The current paper compares the two prominent strategies of allergenic food introduction, gathering the most pertinent modern evidence to distinguish whether exposure to food allergens should be delayed or advanced.
\end{abstract}

Categories: Pediatrics, Preventive Medicine, Allergy/Immunology

Keywords: food allergens, egg, fish, peanut, solid food introduction, allergenic foods exposure, allergy prevention in children, late introduction, early introduction, food allergy

\section{Introduction And Background}

Food allergies among children and adolescents can have various consequences, ranging from minor food sensitivity to the risk of significant complications. Two methods of providing food allergens, namely early and late introduction, are often investigated as the most prominent strategies for preventing food allergies. While some scholars suggest that early exposure to food allergens can be more beneficial in the long term, others argue that late introduction is less dangerous for infants [1,2]. Delayed contact with allergenic materials such as eggs, milk, crustaceans, mollusks, fish, peanuts, tree nuts, soybeans, and wheat has been previously recognized as a leading technique to avoid the development of allergic or autoimmune responses [3]. It is worth noting that the recommendation was only based on experts' opinions as there were no convincing data to support this position at the time. Nevertheless, recent findings demonstrate that late introduction appears to be less efficient in preventing the emergence of food allergies than early allergen contact [4]. Considering the contradicting evidence, it is still unclear whether allergenic foods should be administered in the early or late growth periods to achieve the best possible results.

The trend regarding allergy prevention strategies has been primarily focused on the late introduction of food allergen in infancy with numerous recommendations from official sources, such as the American Academy of Pediatrics, promoting this strategy to accomplish the most productive protective effect [5]. However, contemporary observations from various countries state that late contact might be less efficient when contrasted with early exposure [6]. Furthermore, this strategy may even be ineffective in specific populations and cohorts, resulting in a higher prevalence of food allergies among children and adults [7]. In this regard, as the body of evidence supporting the early introduction approach continues to grow, the contradiction between the two techniques and their benefits for the children becomes more explicit. Therefore, additional studies are required to reduce the knowledge gap and establish the best method for allergy prevention.

Promoting additional research and determining the most secure strategy for food allergy prevention can yield significant benefits for various populations. Given that the severity of food allergies can be a considerable health threat, especially with the emergence of anaphylactic shock, preventing any negative responses can substantially increase the welfare of affected individuals [8]. Ensuring that children safely consume and digest necessary nourishments is a pertinent issue, which could be resolved by establishing the best allergy prevention approach [9]. Furthermore, treating allergic reactions in adulthood is largely complicated and less effective [10]. Altogether, the current medical research must determine whether the early or late introduction of food allergens is the most beneficial for individuals in the long term. 
The present review will discuss whether early introduction of food allergens is more effective in preventing food allergies than the late introduction of food allergens in children. According to current statistics, various food allergies have increased substantially in recent decades, and outgrowing allergic conditions is increasing more public health burden than in previous years $[7,11,12]$. Recently, such supplementary measures as improved research sponsorship and more accurate recommendations were adopted by some organizations [13]. However, even though some health institutions have updated their guidelines and changed their approach to allergy-related studies, the contradiction between early and late introduction remains crucial.

\section{Defining risk and timing of the introduction of some allergenic food}

Infants are grouped high risk or low risk for food allergy development. High-risk infants have at least one parent or sibling with an allergenic condition such as food allergy, asthma, allergic rhinitis, or atopic dermatitis. Low-risk infants do not have the risk factor associated with high-risk infants [14].

The American Academy of Pediatrics in 2000 recommended delaying the introduction of allergenic foods like cow milk until one year of age and seafood or peanut until three years of age for infants at high risk of developing allergy. However, there is no evidence supporting the benefit of avoiding any solid foods beyond four months of age to prevent allergy [14].

\section{Review}

\section{Timing of food allergens and their outcome}

Understanding the available methods of allergy prevention and exploring their aspects have been the focus of several studies. Authors from numerous countries conducted various types of research examining whether delayed exposure to food allergens can contribute to the low prevalence of food allergies in the affected populations and the effect of early introduction in infants $[3,15,16]$. For instance, Ierodiakonou et al. argue that the timing of allergenic food introduction is significant in hindering the development of allergic reactions to particular nourishments, specifically eggs and peanuts, common solid allergens [1]. According to the meta-analysis results, egg introduction at four to six months was associated with a lower risk of egg allergy than later egg introduction, while peanut introduction at age four to 11 months was also associated with a lower risk of peanut allergy [1]. However, early fish exposure was reported to have a low possibility of allergy prevention [17]. Therefore, although early intake of only egg and peanut allergens proved advantageous, this evidence demonstrates that certain foods should be introduced early to avoid future allergic complications. According to the benefits of late and early exposure, presented in Table 1 , summaries highlight how the early introduction of various food allergens is associated with a decreased risk of developing food allergy and other allergies, while the later introduction does the reverse in children concerned.

\begin{tabular}{|c|c|c|c|c|}
\hline Study & $\begin{array}{l}\text { Year of } \\
\text { publication }\end{array}$ & Allergens examined & Effects of early introduction & Effects of late introduction \\
\hline $\begin{array}{l}\text { lerodiakonou } \\
\text { et al. [1] }\end{array}$ & 2016 & Egg, peanut & Lower risk of egg and peanut allergy & $\begin{array}{l}\text { Increase the risk of egg and peanut } \\
\text { allergy }\end{array}$ \\
\hline Kattan [2] & 2016 & $\begin{array}{l}\text { All common food } \\
\text { allergens }\end{array}$ & $\begin{array}{l}\text { Lessened possibility of sensitization, lessened risk } \\
\text { of allergy to all common food allergens }\end{array}$ & $\begin{array}{l}\text { Increased risk of food allergies and other } \\
\text { allergic diseases }\end{array}$ \\
\hline $\begin{array}{l}\text { Tham et al. } \\
\text { [18] }\end{array}$ & 2018 & $\begin{array}{l}\text { All common food } \\
\text { allergens }\end{array}$ & Positive effects for high-risk infants & $\begin{array}{l}\text { Adverse manifestations of eczema for } \\
\text { high-risk children }\end{array}$ \\
\hline West [19] & 2017 & $\begin{array}{l}\text { Peanut, egg, other } \\
\text { food allergens }\end{array}$ & $\begin{array}{l}\text { Diminished risk of developing food allergies, } \\
\text { especially for high-risk infants }\end{array}$ & $\begin{array}{l}\text { Increased risk of allergic reactions in } \\
\text { high-risk children }\end{array}$ \\
\hline $\begin{array}{l}\text { Tham et al. } \\
\text { [6] }\end{array}$ & 2018 & $\begin{array}{l}\text { All common food } \\
\text { allergens }\end{array}$ & Decreased risk of sensitization & Increased risk of sensitization \\
\hline $\begin{array}{l}\text { Burgess et } \\
\text { al. [20] }\end{array}$ & 2019 & $\begin{array}{l}\text { Egg, peanut, } \\
\text { complementary solid } \\
\text { foods }\end{array}$ & $\begin{array}{l}\text { Risk of sensitization decreased, egg and peanut } \\
\text { allergy development hindered }\end{array}$ & $\begin{array}{l}\text { Increased risk of food sensitization, egg, } \\
\text { and peanut allergy development }\end{array}$ \\
\hline $\begin{array}{l}\text { TABLE 1: } \\
\text { early and }\end{array}$ & $\begin{array}{l}\text { Descript } \\
\text { late food }\end{array}$ & allergens introd & $\begin{array}{l}\text { ta-analysis and systematic revie } \\
\text { ction }\end{array}$ & studies on the eftects \\
\hline
\end{tabular}


that introducing allergenic foods to infants between the ages of three to six months is achievable and might decrease the risk of developing food allergy in those children $[4,21]$.

\begin{tabular}{|c|c|c|c|c|c|c|}
\hline Author & $\begin{array}{l}\text { Year of } \\
\text { publication }\end{array}$ & $\begin{array}{l}\text { Number of } \\
\text { participants }\end{array}$ & Location & Allergens examined & Conclusion & Limitations \\
\hline $\begin{array}{l}\text { Perkin } \\
\text { et al. } \\
{[21]}\end{array}$ & 2016 & 1,303 & $\begin{array}{l}\text { United } \\
\text { Kingdom }\end{array}$ & $\begin{array}{l}\text { Cow's milk, peanut, } \\
\text { hen's egg, sesame, } \\
\text { whitefish (cod), and } \\
\text { wheat }\end{array}$ & $\begin{array}{l}\text { Infants can safely be introduced to various food } \\
\text { allergens before six months of age }\end{array}$ & $\begin{array}{l}\text { Lack of } \\
\text { generalization } \\
\text { due to localized } \\
\text { cohorts used }\end{array}$ \\
\hline $\begin{array}{l}\text { Jonsson } \\
\text { et al. [4] }\end{array}$ & 2017 & 65 & Sweden & $\begin{array}{l}\text { Complementary } \\
\text { containing all common } \\
\text { food allergens }\end{array}$ & $\begin{array}{l}\text { Delaying the introduction of complementary foods, } \\
\text { including various allergenic food, increases the risk } \\
\text { of food allergies and other allergic disorders }\end{array}$ & $\begin{array}{l}\text { Small sample of } \\
\text { participants }\end{array}$ \\
\hline $\begin{array}{l}\text { TABLE } \\
\text { of food }\end{array}$ & $\begin{array}{l}\text { 2: Descri } \\
\text { allergens }\end{array}$ & $\begin{array}{l}\text { ption of } \mathrm{s} \\
\text { introduc }\end{array}$ & $\begin{array}{l}\text { elected } \\
\text { tion }\end{array}$ & & ntal studies on the safety & is of tin \\
\hline
\end{tabular}

Considering the outlined findings, this publication introduces a new question to be examined in further research. As the results regarding fish exposure were marked at low certainty, it is essential to identify the reasons behind such patterns and specify other foods that might demonstrate similar trends [4].

Nevertheless, such limitations as lack of relationship between food sensitization and allergic reactions and a small number of studies analyzed should also be noted [22,23]. Furthermore, no distinctions between cohorts were made in the evaluation, and some of the evidence used was retrieved from abstract articles.

The trends reported by Ierodiakonou et al. are highly consistent with other meta-analyses and systematic reviews identifying the efficiency of early egg and peanut allergens introduction [1]. Kattan, Tham et al., and Burgess et al. also provide sufficient evidence that ingesting egg and peanuts in periods four to 11 months can significantly lower the possibility of developing allergic reactions to these nourishments in the future $[2,6,18,20]$. West supports this proposition, presenting evidence that early introduction of peanut and egg allergens is dramatically more beneficial than delayed exposure [19]. Furthermore, high-risk infants and children manifesting signs of eczema and extreme sensitization are most positively influenced by early exposure [24,25]. Nevertheless, West notes that particularly early contact with any allergenic foods has been proven to raise gastrointestinal complications [19]. Thus, an optimal window for introducing food allergens should start at four to six months of age and should be concluded at 12 months, depending on the type of allergen.

Additional evidence regarding low-risk infants is presented in the study by West [19]. It appears that children from the general population can also be positively influenced by the early introduction of egg allergens, challenging previous suggestions that only high-risk infants may develop protection against allergies $[19,26]$. Nonetheless, the number of studies evaluated by West is considerably low, and the majority of them are focused on peanut and egg allergens [19]. In addition, the included articles were not consistently examined regarding their validity and the possibility of biased effects.

Similar to other mentioned articles, this investigation discusses enquiring about tolerance (EAT) research, which evaluated the relationship between low food diversity in early life and subsequent sensitization leading to the development of allergies. The EAT examination is numerously cited in various publications as primary evidence on the benefits of early allergenic food introduction and the demonstration of the multiple foods approach $[27,28]$. Indeed, the majority of contemporary studies focus on egg and peanut as the most prominent causes of allergies in children [29]. On the other hand, EAT explores other common allergens, namely cow's milk, peanut, hard-boiled egg, sesame, whitefish, and wheat [21]. The authors record that the prevalence of food allergies, in general, was significantly decreased after the early exposure to allergens, while delayed contact resulted in a $7.3 \%$ prevalence, which is a considerable gap [21]. Nonetheless, early and late introduction of other allergens, namely cow's milk, sesame, fish, and wheat, appeared to have no distinction in the development of either sensitization or allergies [30,31]. Therefore, the authors propose that less potent allergens are less dependent on the timing of exposure.

Apart from the aforementioned outcomes, the most beneficial finding of this study is the parental attitude toward allergenic food introduction. It was shown that there is another distinction between the early and delayed food consumption in infants, which is referred to as the predicament in feeding techniques [27]. However, the focus on parental impressions is one of the disadvantages of the research, which is extensively directed toward uncovering the mechanisms behind feeding complications. As only $42 \%$ of the overall sample were able to comply with the early introduction requirements, the study lost a remarkable portion of its credibility $[19,32]$. Although the authors note that they attempted to adjust the data according to the 
The examination of the fish allergen's early and late introduction in connection to allergy progression became the goal of one recent study. Jonsson et al. [4] investigated the infants who consumed this nourishment early or after a considerable delay. According to the discovered evidence, exposure to fish can be a significant factor in the development of allergic reactions to other solid foods and an allergy disease in general. The authors claim that nutrients contained in fish products are an essential element of protection against various allergic conditions, especially atopic diseases. Consuming food from an earlier age, such as four to five months, reduces the possibility of manifesting negative responses to various complementary foods, preventing further progression of allergies [33,34]. Therefore, although past studies have presented conflicting evidence concerning the benefits of early allergen intake, this research continues to investigate the significance of timely exposure to these foods.

It is essential to note that this research corroborates previously mentioned assumptions on the topic of negative effects following the late introduction of allergenic foods. While early ingestion of fish and eggs might prevent such ramifications as food allergies, asthma, and atopic diseases, delaying this contact can adversely affect children [35]. Information retrieved after the experimental intervention indicates that children who consumed allergens after 10 months of age were less protected against sensitization and allergy development, demonstrating a higher prevalence of allergies among this population [36]. This outcome has been observed not only in high-risk infants but also in standard-risk cohorts, strengthening the previously made propositions that all categories of young generations might benefit from early exposure to certain allergens.

Finally, an exceptional idea related to the attributes of allergy development is discussed in this study. Relying on past research, the authors note that high food diversity can be a prominent factor in the protection against allergic reactions in the future [37]. Although only a small sample of articles have conducted empirical investigations focused on the multiple foods approach, a tendency toward this method of experimentation can already be sighted [38-40]. In comparison with the delayed introduction of numerous foods, early exposure to a wide variety of complementary nourishments can significantly increase the strength of the autoimmune system, preventing food allergies in later periods [39,41]. Nonetheless, additional investigations are needed as Jonsson et al. only explore early and late introduction effects on a specific cohort, namely farm-raised and city-raised children [4]. Another drawback is the small sample size, meaning that the statistical power of uncovered impacts might be questionable.

\section{Patterns of exposure to complementary nourishments}

A pertinent complication in the development of food allergies is related to the introduction of other solid foods. Burgess et al. [20] evaluated the ingestion of such complementary foods as potatoes, vegetables, meat, rice, wheat, and cereal. Additionally, an investigation into classic categories of allergens, namely egg, peanut, tree nut, shellfish, fish, and sesame, was performed. Apart from highlighting the benefits of early egg and peanut introduction compared to delayed contact, the study revealed that early and late introduction of complementary foods does not increase the risk of food allergy [42]. However, evidence shows that consuming these products after four months appears to be related to a greater risk of food sensitization while ingesting them before four months is not $[20,43]$. Given that food sensitization might contribute to the development of allergy, this finding is crucial for understanding the relationship between solid foods introduction and allergic manifestations.

It is imperative to state the limitations of the studies performed. Although the statistical calculations and analyses were of high quality, a substantial number of the investigations included in the evaluation contained such problems as lack of population heterogeneity and differences between allergy risks [22]. Moreover, the standards of allergic reaction confirmation varied significantly, with only a minority of publications involving the standard oral food challenge [44]. Therefore, even though this article provides an insight into the development of food allergies after early and late exposure to complementary foods, the results of the investigation should be considered with caution.

Other specific food allergies are assessed in a recent systematic review focused on the rise in food allergy prevalence among the contemporary generations. Kattan claims that a recent increase in the likelihood of developing an allergic reaction to certain foods may indicate that the implemented methods are not as effective in battling this phenomenon, necessitating an improvement [2]. Another common type of allergenic food, milk, is evaluated in this study, introducing novel considerations regarding allergy introduction. According to the analysis, the timing of food introduction is highly crucial, and early exposure to milk can alleviate the negative consequences of an allergy progression $[2,45,46]$. However, given the small sample of included studies and limitations in the application of review strategies, evidence from this article should also be interpreted with additional caution.

\section{Insights from Asian-focused research}

While some studies report that Asian children obtain almost no protection from early introduction, others suggest that there is a distinct trend of sensitization for these individuals. According to Tham et al., allergy 
detection and prevention patterns vary substantially for Asian children, who demonstrate unique reactions toward the aforementioned strategies [18]. While for high-risk infants suffering from severe eczema and atopic dermatitis, a delayed introduction constitutes a considerable risk of developing an allergy in the future, and no credible data are available for medium-risk and low-risk children $[6,47]$. Furthermore, current investigations have shown that only peanut and egg allergens might negate the onset of allergic complications in Asian populations, and no findings have been reported considering other foods [48,49]. Therefore, with respect to the low prevalence of egg and peanut allergies in these ethnicities, supplementary examinations are required to establish a credible connection between the benefits of early and late introduction of food allergens. Currently, this approach appears to be advantageous only for highrisk infants.

The importance of the highlighted studies for the overall understanding of the discussed phenomenon is exceptionally high. An essential consideration is a novel perspective from Asian representatives, who are less susceptible to the most researched allergens. However, it is imperative to note that the investigations included in the study by Tham et al. were not examined for biases and contradictions, decreasing the quality of the conducted review and the presented findings [18]. Moreover, as only a small amount of evidence is available on this topic, the nature of the investigation remains exploratory, meaning that the results cannot be generalized and necessitate additional support from experimental research [50,51]. As for Tham et al., the conclusions of the statistical analysis appear contradictory, as only slight significance was found for the suggested correlations, and the number of participants involved in the study is low [6].

\section{Limitations}

The current review possesses several limitations to be considered. A prominent disadvantage is an underdeveloped body of research in this sphere, as additional evidence and data are required to establish a consistent pattern. After that, a significant number of discussed meta-analyses do not examine potential biases or experimental fallacies, thus decreasing the credibility of acquired information. Furthermore, as only a small portion of empirical investigations are included, this paper does not properly evaluate independent experimental data, relying on the summarized findings.

\section{Conclusions}

To conclude, the two prominent strategies of food allergy prevention in children, namely early and late introduction to food allergens, were reviewed in detail in this article according to the recent academic literature. It appears that the timing of allergenic food consumption can tremendously impact the subsequent development of allergic reactions to various types of nourishments, from solid and complementary foods to specific allergens. The research evaluated has established that early exposure, between four to six months to primary allergenic foods, can be more efficient in preventing the emergence of food allergies in children and adolescents. In this regard, the early introduction of food allergens is especially beneficial for children. Compared with late consumption, it can remarkably strengthen the immune system, preventing adverse complications in the future.

This review article provides a necessary insight into the problem of food allergy prevention in children and adolescents, which continues to rise substantially every year. Further investigations on this topic, especially the multiple foods approach, should be conducted. The adaptation of recent findings and the summary of the most significant articles in this area of investigation substantially benefit research on food allergy prevention. Finally, future studies can utilize the present review to provide an overview of contemporary approaches to food allergy prevention.

\section{Additional Information \\ Disclosures}

Conflicts of interest: In compliance with the ICMJE uniform disclosure form, all authors declare the following: Payment/services info: All authors have declared that no financial support was received from any organization for the submitted work. Financial relationships: All authors have declared that they have no financial relationships at present or within the previous three years with any organizations that might have an interest in the submitted work. Other relationships: All authors have declared that there are no other relationships or activities that could appear to have influenced the submitted work.

\section{References}

1. Ierodiakonou D, Garcia-Larsen V, Logan A, et al.: Timing of allergenic food introduction to the infant diet and risk of allergic or autoimmune disease: a systematic review and meta-analysis. JAMA. 2016, 316:118192. 10.1001/jama.2016.12623

2. Kattan J: The prevalence and natural history of food allergy . Curr Allergy Asthma Rep. 2016, 16:47. 10.1007/s11882-016-0627-4

3. Larson K, McLaughlin J, Stonehouse M, Young B, Haglund K: Introducing allergenic food into infants' diets: systematic review. MCN Am J Matern Child Nurs. 2017, 42:72-80. 10.1097/NMC.0000000000000313

4. Jonsson K, Barman M, Brekke HK, Hesselmar B, Johansen S, Sandberg AS, Wold AE: Late introduction of fish and eggs is associated with increased risk of allergy development - results from the FARMFLORA birth 
cohort. Food Nutr Res. 2017, 61:1393306. 10.1080/16546628.2017.1393306

5. American Academy of Pediatrics: Committee on Nutrition. Hypoallergenic infant formula . Pediatrics. 2000, 106: 346-9. 10.1542/peds.106.2.346

6. Tham EH, Shek LP, Van Bever HP, Vichyanond P, Ebisawa M, Wong GW, Lee BW: Early introduction of allergenic foods for the prevention of food allergy from an Asian perspective: an Asia Pacific Association of Pediatric Allergy, Respirology \& Immunology (APAPARI) consensus statement. Pediatr Allergy Immunol. 2018, 29:18-27. 10.1111/pai.12820

7. Bergmann KC, Heinrich J, Niemann H: Current status of allergy prevalence in Germany: position paper of the Environmental Medicine Commission of the Robert Koch Institute. Allergo J Int. 2016, 25:6-10. 10.1007/s40629-016-0092-6

8. Gernes R, Brokamp C, Rice GE, et al.: Using high-resolution residential greenspace measures in an urban environment to assess risks of allergy outcomes in children. Sci Total Environ. 2019, 668:760-7. 10.1016/j.scitotenv.2019.03.009

9. Du Toit G, Foong RX, Lack G: The role of dietary interventions in the prevention of IgE-mediated food allergy in children. Pediatr Allergy Immunol. 2017, 28:222-9. 10.1111/pai.12711

10. Mahdavinia M: Food allergy in adults: presentations, evaluation, and treatment . Med Clin North Am. 2020, 104:145-55. 10.1016/j.mcna.2019.08.008

11. Tang ML, Mullins RJ: Food allergy: is prevalence increasing? . Intern Med J. 2017, 47:256-61. 10.1111/imj. 13362

12. Lyons SA, Clausen M, Knulst AC, et al.: Prevalence of food sensitization and food allergy in children across Europe. J Allergy Clin Immunol Pract. 2020, 8:2736-46.e9. 10.1016/j.jaip.2020.04.020

13. Carletti C, Pani P, Monasta L, Knowles A, Cattaneo A: Introduction of complementary foods in a cohort of infants in Northeast Italy: do parents comply with WHO recommendations?. Nutrients. 2017, 9:34. 10.3390/nu9010034

14. Chan ES, Cummings C, Atkinson A, et al.: Dietary exposures and allergy prevention in high-risk infants: a joint position statement of the Canadian Society of Allergy and Clinical Immunology and the Canadian Paediatric Society. Allergy Asthma Clin Immunol. 2014, 10:45. 10.1186/1710-1492-10-45

15. Al-Saud B, Sigurdardóttir ST: Early introduction of egg and the development of egg allergy in children: a systematic review and meta-analysis. Int Arch Allergy Immunol. 2018, 177:350-9. 10.1159/000492131

16. Waidyatillake NT, Dharmage SC, Allen KJ, et al.: Association between the age of solid food introduction and eczema: a systematic review and a meta-analysis. Clin Exp Allergy. 2018, 48:1000-15. 10.1111/cea.13140

17. Muraro A, Arasi S: Solid foods should be introduced into susceptible infants' diets early in life-CON . Ann Allergy Asthma Immunol. 2019, 122:586-8. 10.1016/j.anai.2019.03.026

18. Tham EH, Lee BW, Chan YH, et al.: Low food allergy prevalence despite delayed introduction of allergenic foods: data from the GUSTO cohort. J Allergy Clin Immunol Pract. 2018, 6:466-75.e1. 10.1016/j.jaip.2017.06.001

19. West C: Introduction of complementary foods to infants. Ann Nutr Metab. 2017, 70 Suppl 2:47-54. 10.1159/000457928

20. Burgess JA, Dharmage SC, Allen K, et al.: Age at introduction to complementary solid food and food allergy and sensitization: a systematic review and meta-analysis. Clin Exp Allergy. 2019, 49:754-69. 10.1111/cea.13383

21. Perkin MR, Logan K, Marrs T, Radulovic S, Craven J, Flohr C, Lack G: Enquiring About Tolerance (EAT) study: feasibility of an early allergenic food introduction regimen. J Allergy Clin Immunol. 2016, 137:147786.e8. 10.1016/j.jaci.2015.12.1322

22. de Silva D, Halken S, Singh C, et al.: Preventing food allergy in infancy and childhood: systematic review of randomised controlled trials. Pediatr Allergy Immunol. 2020, 31:813-26. 10.1111/pai.13273

23. Gray DJ: Egg consumption in pregnancy and infancy: advice has changed . J Health Visit. 2019, 7:68-77. 10.12968/johv.2019.7.2.68

24. Fleischer DM, Sicherer S, Greenhawt M, et al.: Consensus communication on early peanut introduction and prevention of peanut allergy in high-risk infants. Pediatr Dermatol. 2016, 33:103-6. 10.1111/pde.12685

25. Natsume O, Kabashima S, Nakazato J, et al.: Two-step egg introduction for prevention of egg allergy in high-risk infants with eczema (PETIT): a randomised, double-blind, placebo-controlled trial. Lancet. 2017, 389:276-86. 10.1016/s0140-6736(16)31418-0

26. Caffarelli C, Di Mauro D, Mastrorilli C, Bottau P, Cipriani F, Ricci G: Solid food introduction and the development of food allergies. Nutrients. 2018, 10:1790. 10.3390/nu10111790

27. Fisher HR, Du Toit G, Bahnson HT, Lack G: The challenges of preventing food allergy: lessons learned from LEAP and EAT. Ann Allergy Asthma Immunol. 2018, 121:313-9. 10.1016/j.anai.2018.06.008

28. Logan K, Perkin MR, Marrs T, et al.: Early gluten introduction and celiac disease in the EAT Study: a prespecified analysis of the EAT randomized clinical trial. JAMA Pediatr. 2020, 174:1041-7. 10.1001/jamapediatrics.2020.2893

29. Kelleher MM, Jay N, Perkin MR, et al.: An algorithm for diagnosing IgE-mediated food allergy in study participants who do not undergo food challenge. Clin Exp Allergy. 2020, 50:334-42. 10.1111/cea.13577

30. Navard-Keck A, Varshney P: Efficacy of the inquiring about tolerance (EAT) study among infants at high risk of developing food allergy. Pediatrics. 2020, 146:346. 10.1542/peds.2020-02386100

31. Adatia A, Clarke AE, Yanishevsky Y, Ben-Shoshan M: Sesame allergy: current perspectives. J Asthma Allergy. 2017, 10:141-51. 10.2147/JAA.S113612

32. Turner PJ, Campbell DE: Implementing primary prevention for peanut allergy at a population level . JAMA. 2017, 317:1111-2. 10.1001/jama.2017.0922

33. Clausen M, Jonasson K, Keil T, Beyer K, Sigurdardottir ST: Fish oil in infancy protects against food allergy in Iceland: results from a birth cohort study. Allergy. 2018, 73:1305-12. 10.1111/all.13385

34. De Martinis M, Sirufo MM, Viscido A, Ginaldi L: Food allergy insights: a changing landscape . Arch Immunol Ther Exp (Warsz). 2020, 68:8. 10.1007/s00005-020-00574-6

35. Turati F, Bertuccio P, Galeone C, et al.: Early weaning is beneficial to prevent atopic dermatitis occurrence in young children. Allergy. 2016, 71:878-88. 10.1111/all.12864 
36. Klingberg S, Brekke HK, Ludvigsson J: Introduction of fish and other foods during infancy and risk of asthma in the All Babies In Southeast Sweden cohort study. Eur J Pediatr. 2019, 178:395-402. 10.1007/s00431-018-03312-5

37. Perkin MR, Logan K, Tseng A, et al.: Randomized trial of introduction of allergenic foods in breast-fed infants. N Engl J Med. 2016, 374:1733-43. 10.1056/NEJMoa1514210

38. Cukrowska B: Microbial and nutritional programming: the importance of the microbiome and early exposure to potential food allergens in the development of allergies. Nutrients. 2018, 10:1541. 10.3390/nu10101541

39. Markevych I, Standl M, Lehmann I, von Berg A, Heinrich J: Food diversity during the first year of life and allergic diseases until 15 years. J Allergy Clin Immunol. 2017, 140:1751-4.e4. 10.1016/j.jaci.2017.08.011

40. D'Auria E, Peroni DG, Sartorio MU, Verduci E, Zuccotti GV, Venter C: The role of diet diversity and diet indices on allergy outcomes. Front Pediatr. 2020, 8:545. 10.3389/fped.2020.00545

41. Venter C, Maslin K, Holloway JW, Silveira LJ, Fleischer DM, Dean T, Arshad SH: Different measures of diet diversity during infancy and the association with childhood food allergy in a UK birth cohort study. J Allergy Clin Immunol Pract. 2020, 8:2017-26. 10.1016/j.jaip.2020.01.029

42. Krawiec M, Fisher HR, Du Toit G, Bahnson HT, Lack G: Overview of oral tolerance induction for prevention of food allergy: where are we now?. Allergy. 2021, 76:2684-98. 10.1111/all.14758

43. Tran MM, Lefebvre DL, Dai D, et al.: Timing of food introduction and development of food sensitization in a prospective birth cohort. Pediatr Allergy Immunol. 2017, 28:471-7. 10.1111/pai.12739

44. Greiwe J: Oral food challenges in infants and toddlers. Immunol Allergy Clin North Am. 2019, 39:481-93. 10.1016/j.iac.2019.07.003

45. Greer FR, Sicherer SH, Burks AW: The effects of early nutritional interventions on the development of atopic disease in infants and children: the role of maternal dietary restriction, breastfeeding, hydrolyzed formulas, and timing of introduction of allergenic complementary foods. Pediatrics. 2019, 143:e20190281. 10.1542/peds.2019-0281

46. Onizawa Y, Noguchi E, Okada M, Sumazaki R, Hayashi D: The association of the delayed introduction of cow's milk with IgE-mediated cow's milk allergies. J Allergy Clin Immunol Pract. 2016, 4:481-8.e2. 10.1016/j.jaip.2016.01.012

47. Leung AS, Leung NY, Wai CY, Leung TF, Wong GW: Allergen immunotherapy for food allergy from the Asian perspective: key challenges and opportunities. Expert Rev Clin Immunol. 2019, 15:153-64. 10.1080/1744666X.2019.1554432

48. Tezuka J, Sanefuji M, Ninomiya T, et al.: Possible association between early formula and reduced risk of cow's milk allergy: The Japan Environment and Children's Study. Clin Exp Allergy. 2021, 51:99-107. 10.1111/cea.13761

49. Jiang X, Shen C, Dai Y, et al.: Early food allergy and respiratory allergy symptoms and attentiondeficit/hyperactivity disorder in Chinese children: a cross-sectional study. Pediatr Allergy Immunol. 2018, 29:402-9. 10.1111/pai.12888

50. Kim M, Lee JY, Jeon HY, et al.: Prevalence of immediate-type food allergy in Korean schoolchildren in 2015: a nationwide, population-based study. Allergy Asthma Immunol Res. 2017, 9:410-6. 10.4168/aair.2017.9.5.410

51. Thong BY, Arulanandam S, Tan SC, et al.: Shellfish/crustacean oral allergy syndrome among national service pre-enlistees in Singapore. Asia Pac Allergy. 2018, 8:e18. 10.5415/apallergy.2018.8.e18 